\title{
Exclusive Contracts Foster Relationship-Specific Investment
}

\author{
David de Meza ${ }^{1}$ \\ and \\ Mariano Selvaggi $i^{2}$ \\ ${ }^{1} L S E$ \\ ${ }^{2}$ CMPO, The University of Bristol
}

June 2004

\begin{abstract}
Exclusive contracts prohibit one or both parties from trading with anyone else. Contrary to earlier findings, notably Segal and Whinston (2000), we show that investments that are specific to the contracted parties may be encouraged. Results depend on the nature of the investments and whether the bargaining is cooperative or non-cooperative. The major part of the analysis show that exclusive contracts designed to "assure" the supply of essential inputs promote investment. Infinite penalties for breach, even if ex post renegotiable, may result in excessive investment, in which case a finite penalty for breach achieves the first-best outcome.
\end{abstract}

Keywords: Exclusive Dealing, Non-cooperative Bargaining, Liquidated Damages, Renegotiation, Resale

JEL Classification: C70, D23, L42

\section{Acknowledgements}

We thank the Leverhulme Trust for funding this research. Ken Binmore and Jozsef Sakovics provided very helpful comments.

\section{Address for Correspondence}

$\underline{\text { m.selvaggi@bristol.ac.uk }}$

Department of Economics

University of Bristol

12 Priory Road

Bristol

BS8 1TN 


\section{Non-technical summary}

Exclusive contractual agreements entail the acceptance by one or both parties to the contract of limitations on the freedom to individually deal with others for the duration of the cont ract. The present paper examines whether or not these exclusivity provisions serve the socially useful purpose of encouraging ( unveri..able) relation ship-speci..c investments within contexts char acterised by partial contractual incompleteness, that is to say, in situations where the terms of future trade cannot be fully speci..ed in a contract veri..able in courts of law.

Following the burgeoning Proper ty R ights liter ature, we de..ne a relation shipspeci..c (or idiosyncratic) investment as one that is highly valuable inside a particular business partnership but that has extremely low or eventually no value whatsoever outside it. A mine-mouth (coal) plant built by an electric utility represents a good illustrative example. In exect these productive units locate adjacent to coal reserves from which the coal is mined for the plant, where electrical power is ..rst generated and then transmitted through high voltage transmission systems to load centres. It is well known that mine-mouth plants involve substantial durable relationship-speci..c investments (e.g., in transmission capacity or in specialised productive machines) because they are conceived to purchase and burn the particular type of coal existing in the adjacent mine over the life of the plant. The use of coal that dixers from the original design speci...cations leads to both important losses in thermal ed ciency and sharp increases in power outages and plant maintenance costs. Since, once the plant is already in place, the operator's outside procurement opportunities are enormously constrained, the utility's investment is bound to be highly relationship speci...c.

At ..rst sight it may seem rather evident that if a ..rm holds an enforceable exclusive-dealing contract that allows it to block trade between its business partner and others, then the exclusive-rightholder will in general be willing to undertake more relationship-speci..c investment. The underlying reasoning is that the exclusivity clause redistributes bargaining power between the parties to the contract, thereby axecting the future distribution of the gains from trade. Clearly the holder of the exclusive contract ends up receiving a bigger share of the ..nal cake. However, whether the exclusive-rightholder's improved bargaining position is ultimately sensitive to its level of speci..c investment is by and large less obvious, and this is indeed one of the main lines of enquiry throughout the remainder of the paper.

The existing literature mostly explains exclusivity as a device to eliminate horizontal externalities that give rise to inec cient outcomes. In particular, it has been argued that exclusive dealing sometimes encourages speci..c investment because it curbs certain (intra- and inter-brand) free-riding problems that arise whenever a party's investment has - at least to an appreciable extent positive spillovers on non-investing parties. For instance, a manufacturer may grant an exclusive dealership for a territory so as to restore incentives for the retailer to invest in surplus-enhancing services and/ or local promotions that 
would otherwise bene.t other retailers located in the same geographical area and carrying the manufacturer's brand. The reason is that without exclusive dealing the services become a public good on which the retailers will free ride, thus triggering an underprovision result, whereas with an exclusivity agr eement incentives are sharpened because the contracted retailer ap propriates the whole bene..t from its investment.

The aforementioned argument, although intuitively compelling, entails investments that are not entirely relationship speci..c. In exect the presence of so-called external exects implies that the manufacturer will bene.t from the investment made by a particular retailer even when dealing with other retailers. In contrast, we ..x attention on a vertical st ructure comprising a supplier of an indispensable good and two downstream customers in which one of the (riskneutral) buyers faces a risky investment opportunity that only creates a surplus if he has access to the seller's product. Hence in our set up the buyer's investment exhibits no externality whatsoever on others. Signi..cantly, it is precisely under these circumstances that earlier ..ndings, most notably Segal and W hinston (2000), claim that contractually locking parties together is neutral with respect to investment in the partnership and that exclusive contracts are thus devoid of any substantive content. The major part of our theoretical analysis demonstrates, however, that an exclusivity provision designed to "assure" the supply of an essential input unambiguously promotes the buyer's investment. Indeed this seems to bring the theory much closer to the empirical evidence.

The above discrepancy in our respective predictions owes in part to the fact that Segal and W hinston assume initial "non-cooperative" investment decisions are followed by "cooperative" bargaining over the division of the ..nal surplus. Such a mixed approach has many precedents in multi-stage bargaining models, but tractability aside, it is not always clear why dixerent solution concepts apply at dixerent stages of the game. Furthermore cooperative solution concepts leave the bargaining process unmodelled and are generally best justi..ed as incorporating notions of justice or fairness. We allege that this is not obviously an appropriate basis for positive economics. For example, ..rms that fail to trade in the marketplace or job candidates that are ..nally turned down do not in reality normally receive compensatory payments from those that do, as it is actually implied by the cooperative models frequently used in the industrial economics liter ature. Interestingly enough, in this paper we contrive to provide a theoretical framework that is not marred by those unrealistic features.

The chief modelling problem is that exclusive-dealing contracts only make sense if at least three parties have an interest in the ..nal outcome. Trilateral non-cooperative bargaining solutions are, however, notoriously delicate. This may explain the preference for using cooperative bargaining to determine the split of the surplus. In that connection, an extra contribution of this paper is to set forth a novel three-agent bargaining model which allows us to show that under plausible non-cooperative bargaining assumptions, exclusivity deals are bene..cial for relat ionship-speci...c investment because they axect marginal as well as total payous. Thus, our conclusions support existing informal arguments that emphasize the link existing between an exclusionary provision and the 
investment incentives of its recipient, thereby challenging Segal and W hinston's claims to the contrary. Furthermore we ..nd that in..nite penalties for breach of contract, even if ex post renegotiable, may in fact result in excessive investment from an eф ciency point of view, in which case a ...nite penalty for breach achieves the ..rst-best outcome. 


\section{Introduction}

A burgeoning literature examines how to mitigate hold-up problems created by incomplete contracts. Less attention has been paid as to why ..rms sometimes deliberately expose themselves to the threat of hold-up. That after all is the consequence of exclusivedealing contracts so frequently adopted when legal. of course there is no real paradox. Exclusive contracts, by prohibiting trade with third parties, redistribute ex post bargaining power. ${ }^{1}$ If one side of the transaction is more vulnerable to hold up, the other is less so. As a result, exclusive contracts may stimulate relationship-speci..c investment.

In contrast, Segal and W hinst on (2000) ...nd that contractually locking parties together is neut ral with respect to investment in the relationship. This is in part because they assume initial "non-cooperative" investment decisions are followed by "cooper ative" bargaining over the division of the surplus [see also Segal (2003) ]. ${ }^{2}$ Such a "mixed" approach has many precedents in multi-stage bargaining models, but tractability aside, it is not clear why dixerent solution concepts apply at dixerent stages. Cooperative solution concepts leave the bargaining process unmodelled but are generally best justi..ed as incorporating notions of justice or fairness. This is not obviously an appropriate basis for positive economics. ${ }^{3}$ For example, ..rms that fail to trade in the market do not in reality normally receive compensat ory payments from those that do, as is implied by most cooperative bargaining solutions (this is made explicit in Section 2).

The modelling problem is that exclusive-dealing contracts only make sense if at least three parties are involved. Trilateral non-cooperative bargaining solutions are, however, notoriously delicate. This may explain the preference for using cooperative bargaining to determine the split of the surplus. T he contribution of this paper is to show that under plausible non-cooperative bargaining assumptions exclusivity does matter for investment incentives because it axects marginal as well as total payoxs. Thus, our results support existing informal arguments that emphasize the link existing between an exclusionary provision and the invest ment incentives of its recipient [e.g., K Iein, Crawford and A Ichian (1978), K lein (1988) and Frasco (1991) ], thereby challenging Segal and W hinston's claims to the contrary.

The existing literature mostly explains exclusivity as a device to eliminate horizontal externalities. For example, a manufacturer may grant an exclusive dealership for a territory so as to create incentives to invest in advertising and local promotions that would otherwise bene..t non-investing retailers [e.g. M athewson and Winter (1994) ]. ${ }^{4}$ The key features are that investment is not rela-

\footnotetext{
${ }^{1} \mathrm{~A}$ requirements contract prevents a buyer dealing with other than the stipulated seller whilst an output contract precludes a seller dealing with any but the speci..ed buyer.

${ }^{2} \mathrm{An}$ important exception is the recent an alysis by Che and Sákovics (2003b). We comment on this paper later.

${ }^{3}$ Cooperative solutions can generally be replicated by some non-cooperative bargaining protocol. Segal and Whinst on show that this applies to their case. However, those noncooperative games often invol ve rather arbitrary assumptions that seem dic cult to defend.

${ }^{4}$ Technological externalities and the attempt to curb free riding al so underlie the exclusionary provisions analysed by $M$ athewson and W inter (1987), M arvel (1982), B esanko and Perry
} 
tionship speci..c and not all those capable of bene.ting from it sign the exclusive contract. In contrast it is assumed here that investment is only of value to two parties. It is then that Segal and W hinston claim that exclusive contracts are pointless.

To show that this need not be so consider an example similar to that of Segal and Whinston (p. 608). A buyer desires a unit of an input available in generic form from a competitive industry at price equal to production cost $c$. The buyer values the good at $v>c$. There is a seller able to tailor the good to the buyer's speci..c requirements. The modi..ed product is no more costly for the seller to produce whilst the buyer's valuation increases to $v+\phi$. For this bene.t to be realised, both the buyer and seller must each make unveri..able investments of $i$ before production takes place, where $\phi>2 i>0$ (perfect complementarity is not necessary for the results or even double sided investment). Thus investment is eq cient and does not exhibit external exects because it only axects the value derived from trade between the two of them. For the buyer, the investment costs may be informing the seller of what is needed to enhance value or of adapting plant to use the modi..ed input or of promoting a superior ...nal good.

If both investments are undertaken but the good is not yet produced there is a surplus of $v+\phi i$ c to divide. At this point a binding price can be negotiated. The bargaining protocol is an in..nite-horizon $\mathrm{R}$ ubinstein alt ernating-oxer game. We take the limit as the interval between rounds shrinks to zero. The buyer could purchase a generic good on the competitive market so has outside option $v \mathbf{i} c$. For the seller the best alternative is to produce for the market, in which case their joint surplus is zero. As is st andard, the buyer's outside option binds if $v \mathbf{i} c>0.5(v+\$ \mathbf{i} c)$ or $v \mathbf{i} c>\$$. If this condition holds the tailored good is sold for $c+\phi$ and the buyer's gross surplus is the same as when not investing. Hence investing cannot be an equilibrium.

Now consider the situation if there is an exclusive contract that prohibits the buyer acquiring the good from any but the contracted seller. ${ }^{5}$ This eliminates the buyers outside option so the surplus is split equally. Both buyer and seller investing is thus an equilibrium if $0.5(v+\phi ; c) ; 0.5(v \mathbf{i} c)=0.5 \phi>i$. Exclusivity brings about investment if and only if investment is ed cient. ${ }^{6} \mathrm{~T}$ he set up resembles a franchise where, as Klein and Saft (1985) document, it is common that the franchisee (the buyer) must obtain inputs from franchisor (the seller) rather than on the open market. The usual explanation for this practice is quality control but our analysis shows that investment incentives, especially for the franchisor, may be involved.

(1993) M asten and Snyder (1993) and Bernheim and Whinston (1998). See Motta (2004) for a recent discussion of these arguments.

${ }^{5}$ When the contract is signed any necessary transfer payments can be made.

${ }^{6} \mathrm{~T}$ his does not preclude other ex ante contracts being helpful. Giving the buyer an option to buy at a prespeci..ed price achieves eq ciency as long as price is not negotiable ex post. Unlike an exclusi ve contract, with double-sided smooth investment such a scheme can achieve the ..rst-best outcome. The assumption that the price can be committed to is a strong one. It requires that the seller can be compelled to deliver, but since quality is not veri..able oxering a generic product and having it turned down would vitiate the contract and then allow free bargaining over the ad apted good. 
The outside-option example of W hinst on and Segal involves a seller able to invest to lower its production cost. Absent the exclusive contract, the buyer has a binding outside option from the opportunity to acquire the good on the competitive market. Thus the seller, whose good is by assumption worthless in the competitive market, is residual claimant and captures the full marginal bene..t to the relationship of their investment. Under exclusivity the split-thesurplus solution applies and so the seller's investment incentive is diminished at the margin.

What our version shows is that the conclusion that exclusivity is bad for investment depends on which parties invest. In the main part of their paper Segal and Whinston analyse much more general investment structures but combine this with a cooperative bargaining solution that precludes reasonable non-cooperative outcomes that reverse their result.

In the rest of our paper we do not invoke a competitive sector but provide an explicit three-agent model where all parties engage in non-cooperative bargaining. W hether or not the outside-option principle applies we show that exclusive contracts may be bene..cial for relationship-speci..c investment. The setting is of a risk-neutral buyer with a risky investment opportunity only investing if the supplier of an essential input contracts not to sell it elsewhere. ${ }^{7}$

In modelling the bargaining over the intermediate input we assume that resale is feasible. This is not only realistic in many contexts but cuts through some of the modelling di $\$$ culties otherwise encountered in three-party bargaining. The proposed trading game is set forth in the companion paper by Selvaggi (2003). In this context it implies that exclusive dealing not only encourages investment but may give rise to overinvestment, though this can be controlled by suitable breach remedies.

The remainder of the Introduction provides an example to illustrate the gist of our main analysis. ${ }^{8}$ A seller possesses a single unit of an indivisible good, which can be used productively by two potential customers. Perhaps the seller is an input monopolist and the potential customers are two downstream ..rms. Each downstream buyer seeks to buy at most one unit of the intermediate in put and one can invest to enhance the value of obtaining the good though returns are stochastic.

First, the ex-post bargaining solution will be sketched. ${ }^{9}$ Suppose buyer 1 obtains payos 6 from use of the good whereas buyer 2's use value is 8 . The

\footnotetext{
${ }^{7}$ Using a rather dix erent setting, M cA xe and Schwartz (1994) conclude that in multilateral contexts exclusivity can protect customers from ex post opportunism. However, their result stems from the assumption that downstream ..rms produce (perfect or imperfect) substitute products, which in the absence of exclusive dealing generates negative externalities among the buyers. In this paper we assume instead that downstream ..rms do not compete on the product market.

${ }^{8}$ T hese exam ples u se the sub game-perfect equilib rium outcomes of our three-party bargaining game when the interval between successive proposals becomes vanishingly small. Section 2 in this paper dicusses further details of this model, whereas Selvaggi (2003) gives a thor ough discussion of the underlying non-cooperative game.

${ }^{9} \mathrm{As}$ usual in these kinds of non-cooperative bargaining settings, a coalition between the buyers (e.g. a legally binding collusive agreement) is ruled out by assumption.
} 
seller's valuation is normalised to zero. A key ingredient in determining the price at which the good is sold is our assumption that if buyer 1 (the lowvalue customer) initially acquires the good, negotiations can instantly be opened up with buyer 2 to resell it. This second-stage price determination game is a two-party bargaining problem to which the Nash "split-the-dixerence" rule applies; that is, the price equals the owner's use value plus half of the surplus created by the transfer. The item is thus sold on to buyer 2 (the high-value customer) at price 7. The ..nal allocat ion of the good is therefore Pareto ed cient. T he non-cooper ative bargaining underlying the resale equilibrium is a standard alternating-oxer game with random selection of proposer, in which there is no discounting but a vanishingly small exogenous chance of breakdown in each round that prevents further negotiations between the agents. ${ }^{10}{ }^{11}$ Crucially, that agents know that if buyer 1 obtains the good at the ..rst stage it will be resold to buyer 2 at price 7 shapes willingness to pay when negotiating with the seller at the outset.

In the ..rst stage of the game, as in Calvó-Armengo (1999), the seller is the central player and alternately meets each buyer. W hich party is then proposer is decided at random. If the oxer is rejected, the seller then moves to the other buyer. The procedure continues until there is agreement but there is again a small chance in each round that negotiations irretrievably break down, in which case the seller is left with the good. ${ }^{12}$

Although the two buyers dixer in the use they can make of the good, the resale opportunity means that neither would pay more than 7 for the item at the ..rst stage. M or eover, if a buyer's failure to reach agreement with the seller is followed by the other buyer agreeing next period, then neither buyer would reject a price of 7 or less. W hat is implied is that the good is instantly sold for 7. ${ }^{13}$

\footnotetext{
${ }^{10}$ See, e.g., Binmore et al. (1986), O sborne and Rubinstein (1990) and M uthoo (1999). For other recent applications of th is bargaining solution, see Che and Sákovics (2003b) and Stole and Zwiebel (1996).

${ }^{11}$ As shown by Binmore (2003), the unique subgame-perfect equilibrium of this two-party bargaining converges to the $\mathrm{N}$ ash bargaining solution for the problem $(X, b, b)$, where the breakdown/deadlock point is $b={ }^{\prime} v^{L}, 0$. Since in our case the buyers' bargaining powers are identical, the equilibrium value of resal e locates hal fway between the val uations of the two buyers.

${ }^{12} \mathrm{~A}$ plausible cause for such a risk of breakd own is that the owner of the item may get fed up with negotiations, ther eby walking away from the negotiating table and immediately consuming the good. This type of human behaviour is naturally random. O ther interpretations may also be appropriate though. Consider, for example, a "telephone bargaining" model. Speci..cally, the owner of the good phones another player and they exchange oxers over the phone. In this context a breakdown is due to the fact that the owner may randomly hang up at the end of each round and, possibly, then phone another party. Namely, at the ..rst stage of the game the seller hangs up and subsequently phones the other buyer, whereupon the situation repeats itself. A t the resale game, $L$ hangs up and immediately consumes the good -for there is no other agent to phone. B oth interpretations give rise to id entical limiting out comes.

${ }^{13}$ If the entire bargaining game has no risk of breakdown but there is in stead time discounting, the outside-option principle applies. Then, as the interval between successive proposals becomes vanishingly small the resale price obtained by buyer 1 tends to 6 , and th is is the price at which the upstream ..rm sells the good at the ..rst stage [see Sel vaggi (2003) ]. As show $n$ in
} 
To see what this solution implies for exclusive dealing contracts, suppose buyer 1 's use value is indeed equal to 6 whereas buyer 2's is stochastic. There are two equally likely states of the world and before knowing which prevails, buyer 2 is faced with a binary choice. If buyer 2 does not invest, then the good is worth 8 in one state and nothing in the other. Investment costs 1.25 and boosts buyer 2's value of the good by 4 in each state, making it 12 in one state and 4 in the other.

Maximization of expected aggregate surplus clearly requires that buyer 2 invests, but in the absence of exclusive dealing there is underinvestment. A s just noted, when buyer 2 does not invest he pays 7 for the good in the state in which he is the high-value agent. In the event that buyer 2 is the low-value agent his payou is zero. So if buyer 2 does not invest, his expected revenue is ( 8 i 7) $f 0.5=0.5$. If buyer 2 invests the good is obtained in one of the states at a price of $(6+12) £ 0.5=9$. In the other state, as the low-value customer, buyer 2 's payox is zero, so his expected revenue is $(12$; 9$) £ 0.5=1.5$. Investment only raises buyer 2 's gross pay ox by 1 , less than its cost. Thus, due to the standard hold-up problem, there is underinvestment.

In contrast, when the seller enters into an exclusive trade agreement with buyer 2, full eq ciency is achieved. Suppose that buyer 2 chooses to invest. In the state in which his investment succeeds there is bilateral bargaining with the seller, and the good is sold for $(12 ; 0) £ 0.5=6$. In the other realization, once buyer 2 obtains the good it is resold to buyer 1 for $4+(6 ; 4) £ 0.5=$ 5. Therefore, in the ..rst-stage bargaining with the seller, buyer 2 splits the dixerence between 5 and 0 , giving an initial transfer price of 2.5. ${ }^{14}$ Thus, if buyer 2 invests his expected revenue is $(6+2.5) f 0.5=4.25$. U sing the same logic, if buyer 2 does not invest expected revenue is $(4+1.5) f 0.5=2.75$. Investment increases expected revenue by 1.5 , which now exceeds the cost of 1.25. So exclusive dealing creates an eфc cient outcome.

Holding an exclusive-d eal ing contr act naturally enhances the exclusive buyer's bargaining power - his share of the available cake. This does not of itself change the incentive to invest if the payou increases by the same amount whether or not investment is undertaken. This though is not the case. In the absence of an exclusive contract, irrespective of whet her investment has been undertaken, buyer 2 is in exect cut out of the bargaining in the fail state and obt ains zero net payox. With an exclusive contract, the fact that with investment buyer 2 has a

\footnotetext{
the Appendix A.1, a version of our result also applies in this case.

${ }^{14}$ T his result is related to Rubinstein and Wolinsky (1987). T hey study a market con..guration in which there are three types of agents involved in Nash bargaining: sellers, buyers and middlemen. In Rubinstein and Wolinsky's model direct transactions between sellers and buyers are costly due to the time-consuming matching technology that randomly brings them together. These frictions in the trade process enable the middlemen - simple intermediaries in their set up - to capture some rents in return for shortcoming the time period sel lers and buyers must wait until trade takes place. However, Rubinstein and Wolinsky note that if a seller can pass the good to a buyer only through the middleman (e.g., sellers and buyers are almost never matched), then in the seller-middleman bargaining they split the dixerence bet ween the price of resale and zero. T herefore their case is analytically similar to our exclusive-dealing situation in which the seller writes an exclusivity deal with the least ed cient customer.
} 
greater valuation of the good means that at the resale stage a higher price can be negotiated with buyer 1 . Some but not all of this extra second-stage surplus is appropriated by the seller in the ..rst-stage bargaining. When the contracted agent has the highest valuation, the extra gross surplus created by investment is shar ed equally with the seller. W ithout the contract, exactly the same split would occur, though now the mechanism is that the good is worth more to buyer 1 in the resale market and the consequent intensi..ed competition at the ..rst stage pushes up the price. It is the increased payox when the protected buyer does not end up using the good that causes an exclusivity deal to foster incentives to invest. Put dixerently, exclusive dealing increases the sensitivity of the buyer 2's payox to his investment.

This result carries over straightforwardly to the continuous investment case considered later in the paper. In the presence of exclusive dealing, the protected party obtains marginal investment returns even when the low-valuebuyer. These additional returns oxset the detrimental exects of potential hold ups. $M$ oreover, under some circumstances exclusivity may give rise to overinvestment. Exclusive contracts that stipulate ..nite rather than in..nite penalties for breach (i.e., liquidat ed damage clauses) may then be appropriate. They provide some extra investment incentives but limit their magnitude, thereby preventing an excessive investment level by the exclusive buyer.

T he general message of our model is that exclusive dealing can never worsen the contracted party's marginal investment incentives. This stands in sharp contrast to existing claims based on cooperative bargaining. In a cooperative framework, exclusivity merely eliminates the surplus otherwise created by a coalition of the seller and the uncontracted buyer but does not axect what can be achieved by any coalition of which the contracted ..rm is a member. If only the contracted buyer has an investment opportunity, it is immediate that exclusivity cannot enhance marginal investment incentives - nothing changes in any coalition of which he is a member. This is the basis for Segal and W hinston's Ir relevance Result. ${ }^{15}$ In our non-cooper ative set up, exclusive dealing does have a major negative impact on the seller's bargaining payox. This is due to the elimination of competition for the in put (though the contracted ..rm pays for the advantage ex ante). The existence of a subsequent resale market implies that exclusivity does not necessarily impinge on the uncontracted buyer. Rather, it is the exclusive customer who bene..ts from a lower price when he ends up using the good. The key point is that exclusive dealing makes all the dixerence for marginal investment incentives because it makes the protected ..rm's payox sensitive to its investment even when it is not the ultimate user of the good. That exclusivity promotes relationship-speci... investments turns out to be robust to alternative non-cooperat ive bargaining solutions ( see the A p pendix) and is much more in line with the empirical evidence.

\footnotetext{
${ }^{15} \mathrm{~A}$ common theme in these models is that exclusivity axects negatively the uncontracted party's bargaining payox. However, de M eza and Selvaggi (2003) show that this mechanism can in fact be ec ciency-enhancing when both buyers make speci..c investments that are (imperfect) substitutes and do not exhibit technological dependencies. We return to this issue in Section 2.
} 
Che and Sákovics (2003b) also ..nd a role for exclusive contracts under non cooperative bargaining but the mechanism is very dixerent. They utilize their dynamic hold-up model [Che and Sákovics (2003a)] to analyse the relationship between exclusivity and incentives for speci..c investments. Their basic set-up is a dynamic non-cooperative bargaining model with two parties and multi-stage (cumulative) investment opportunities. Roughly speaking, highinvestment equilibria can be sustained because each party has the opportunity to make up for low investment in one period by supplementary expenditures in the future. So, if an agent deviates by investing low, the other party rationally makes a low oxer knowing that the attempt to free ride will be cancelled once the equilibrium path is resumed next period. Thus downward deviations are heavily punished, allowing equilibria that are close to ..rst-best if the chance of breakdown is sul ciently small. If ..rms have good alternative trading opportunities the punishment opport unity is limited. Exclusive contracts are modelled as reducing disagreement payoxs (what the part ies to the contract can get elsewhere if negotiations break down), thereby permitting equilibria with higher investment levels than would otherwise be possible.

Multiple equilibria are intrinsic to this dynamic model. For example, the regular "static" hold-up outcome is also an equilibrium. Che and Sákovics' assumptions imply that exclusivity has no exect on this equilibrium for though the level of disagreement payoms are altered, their sensitivity to relationshipspeci..c investment is not. So in Che and Sákovics exclusivity adds equilibria when the "individual rationality" constraint is binding for a party, whilst in our formulation the nature of the equilibrium alters. This ref ects our recognition that resale possibilities mean that an exclusive contract does not necessarily determine the ..nal user of a good.

Of course the two approaches are complementary, but building a model with both features is left for future work.

The rest of this paper has the following structure. Section 2 describes concisely the central features of our non-cooper ative bargaining game and examines the exects of exclusive dealing on the parties' equilibrium payoxs. Then, Section 3 presents a simple model in which relationship-speci..c investments and potential hold-up problems are also taken into account. This section characterizes incentives for speci..c investment in the nonexclusive and socially optimal benchmark cases, and also explains how in our model exclusivity unambiguously promotes its recipient's investment incentives (see Proposition 5). In addition, it describes the mechanism whereby stipulated penalties for breach of contract (liquidated damage clauses) can on some occasions curb the exclusive party's incentives to overinvestment, thus facilitating the achievement of the ..rst-best outcome. Finally, Section 4 draws conclusions.

\section{Three-party bargaining with resale}

This opening section outlines the major features of the non-cooperative bargaining game applied in the remainder of the paper. The model is based on Selvaggi 
(2003, Section 2), extended to examine the impact of exclusive-deal ing contracts on the parties' subgame perfect equilibrium payoxs. For now we abstract from investment decisions. The solution obtained is utilized in subsequent sections of the paper to evaluate whether exclusivity provisions safeguard against ex post opportunism, ther eby fostering relationship-speci..c invest ments.

The basic game comprises the seller, $S$, of an indivisible good who bargains with two heterogenous buyers, $H$ and $L$, who value the good at $v^{H}$ and $v^{L}$ respectively, with $v^{H}, v^{L}>0$. The use value of the good to $S$ is normalized to zero.

The bargaining protocol is a version of the Rubinstein (1982) alternatingoxer game. Speci...cally, there is no discounting but a probabilistic risk of breakdown in negotiations at the end of each round (the modelling of breakdown is discussed below). The alternative case of discounting but no breakdown possibility proceeds along the same lines but yields an outside option version of the results. This solution is developed in Selvaggi (2003) and applied to exclusive contracts in A ppendix A 1.

Time is divided into periods of equal length, denoted by $\phi>0$, and oxers are made at $0, \$, 2 \phi, \ldots, t \phi, \ldots$ In period 0 the seller is matched with $H$, a proposer is then selected at random (i.e., each player has probability $1 / 2$ of being the proposer), and the other party responds with acceptance or rejection of the proposal. In the case of acceptance, the good is immediately tran sferred to the buyer. Following rejection, negotiations may either break down ir retrievably or reach the next period, in which case the seller is matched with $L$ and the cycle is repeated.

If the seller reaches agreement with $H$, the game immediat ely terminates. However, if $S$ initially trades with $L$, in the following period negotiations may be opened up with $H$ to resell the good. This second-stage price determination subgame is referred to as the "resale stage" or "secondary market", where negotiations again follow an alternating-oxer protocol with random selection of proposer and a chance of breakdown in each round.

The exogenous or "forced" breakdown in negotiations is modelled in the following way [see, e.g., B inmore et al. (1986), Osborne and R ubinstein (1990) and $M$ uthoo (1999)]. At the end of any period $t \$$ (whether at ..rst or resale stage), and independently of a particular oxer being accepted or rejected, with probability $p 2(0,1)$ negotiations irrevocably break down and with probability $(1 \mathbf{i} p)$ the game proceeds to period $(t+1) \phi$. These probabilities are independent of all past events. Although the exogenous breakdown precludes further negotiations between any of the parties, it does not prevent the agent who possesses the good from consuming it instantly. It is easiest to think of breakdown involving the owner of the item walking away from the negotiating table (perhaps he gets fed up with negotiations) and immediately consuming the good. This random human behaviour obviously precludes subsequent bargaining. [Selvaggi (2003) provides alternative interpretations of the breakdown technology.]

So, all the risk-neutral agents are indixer ent about the period in which agreement is reached and have full information about the history of the market at all times. As usual, it is assumed that as the interval between two consecutive 
price oxers decreases, the probability of breakdown between those oxers also decreases. Indeed, we consider the limiting case in which $p$ ! 0 as $\$ ! 0$.

T he bar gaining game is solved by Selvaggi (2003) using backwards induction. The subgame-perfect equilibrium of the secondary market is ..rst obtained and these payoxs used to compute the "unique" equilibrium of the entire game. Here, we simply state the main result together with some intuition.

P roposition 1 In the limit, as $\$$ ! 0 , the unique subgame-perfect equilibrium payous to $S, L$ and $H$ respectively converge to:

$$
\frac{v^{H}+v^{L}}{2}, \quad 0 \text { and } \frac{v^{H} \mathrm{i} v^{L}}{2}
$$

P roof. See Selvaggi (2003, Section 2).

The good is instantly sold to $H$ for ${ }^{\mathrm{i}} v^{H}+v^{L} \Phi / 2$, a price halfway between the valuations of the two buyers (note that if buyers were identical, the seller would capture the entire surplus). As the item always falls into the high-value buyer's hands the bargaining process is et cient. The equilibrium price also coincides with what $H$ would have paid for the good had it been acquired in the secondary market, albeit resale is ox the equilibrium path. ${ }^{16}$ In exect the competition between the buyers at the outset of the negotiations process allows the seller to capture the extra rents generated at the potential resale stage, and $L$ is ultimately left with nothing whatever.

In a sense, the proof of Proposition 1 refects the idea that, in the presence of resale, both buyers behave "symmetrically" even though their use values dixer. Neither buyer would be willing to pay the seller more than ${ }^{1} v^{H}+v^{L} / 2$ at the ..rst stage - that is the equilibrium price in the secondary market. Further, if a buyer's failure to reach agreement with the seller is followed by the other buyer agreeing with the seller next period, then it is clear that neither buyer gains by rejecting a seller's price oxer of $v^{H}+v^{L} / 2$ or less. W hat this implies is that the good is sold instantly to $H$ for an amount that leaves him indixerent between trading with $S$ or $L$. The ..nal payoxs are those of the second-stage subgame and the lowest-value buyer get $s$ nothing. ${ }^{17}$

The conclusion that $L$ ends up with zero is worth emphasizing because it stands in sharp contrast to the predictions of most cooperative bargaining models used in the literature. Consider, for instance, Shapley values. In the case under consjder ation, this cooperative solution gixes rise to the payous vector

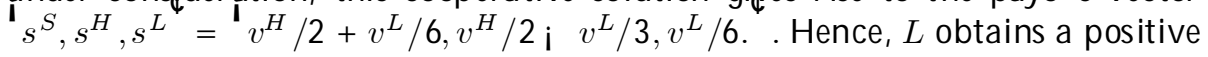

\footnotetext{
${ }^{16}$ Since players are in..nitely patient, when the chance of breakdown becomes vanishingly small the standard "split-the-dixerence" rule applies. As noted by Binmore $(1994,2003)$, in the case under consideration the equilibrium outcome converges to the Nash bargaining solution for the problem $(X, b, b)$, i.e., the breakdown and deadlock points are $b={ }^{L} v^{L}, 0$. So the buyers split the di xerence between $v^{L}$ and $v^{H}$.

${ }^{17} \mathrm{~T}$ his conclusion carries over to a broad range of solution concepts such as out side-option bargaining, bargaining with both forced and unforced breakdowns, and $\mathrm{N}$ ash bargaining [see Selvaggi (2003)]. See also the Appendix in this paper.
} 
payox although he is the low-value customer and therefore never consumes the good [i.e., $L$ contributes nothing to the coalition $\mathrm{f} S, H \mathrm{~g}$ ]. R easonable strategic bargaining games in general do not exhib it this feature [see, e.g., Binmore (1985, 2003), Osborne and Rubinstein (1990) and Bolton and W hinston (1993)]. B y the same token, concepts such as ordering of players and probability distribution over orderings, coalition formation and fairness, all material ingredients of the cooperative frameworks, play no role whatsoever in our strategic model. As we now demonstrate, this non-cooperative approach implies that the exect of exclusivity on the parties' bargaining payoxs is very dixerent to the previous literature.

\subsection{B argaining payous in the presence of exclusivity}

Suppose the seller enters into an "enforceable" exclusive trade agreement with one of the buyers. This exclusivity deal deters $S$ from trading the good with any customer other than the exclusive-righthold er. ${ }^{18}$ Following Segal and W hinston (2000), we also assume that the contract does not specify a positive trade between $S$ and the contracted buyer must take place. Although we later introduce an investment stage and assume that such choices are observable but not veri..able, this does not preclude trades being veri..able (i.e., there is partial exclusive contractual incompleteness). For now we do not explain why an exclusive contract might emerge but merely examine its impact on the players' ex post bargaining payoxs. In the next section we shall study the role of exclusive dealing in a richer economic context comprising speci..c investments and hold-up problems.

The proposed bargaining game easily accommodates an exclusivity provision. When the seller may only trade with the contracted buyer negotiations at the ..rst stage of the game boil down to a two-party bargaining in which, as it is well known, the seller and the contracted buyer split the relevant surplus ( for both agents now have identical bargaining power). That aggregate surplus depends in turn on whether the exclusive buyer consumes the good or resells it to the other buyer.

To be speci..c, sup pose the seller has entered for somereason into an exclusivedealing arrangement with buyer $L$. Once $L$ acquires the good it is resold to buyer $H$ for $v^{L}+v^{H} / 2$. Thus, $S$ and $L$ split the dixerence between ${ }^{1} v^{L}+v^{H}{ }^{H} / 2$ and 0 at the outset, which determines an initial transfer price of ${ }^{1} v^{L}+v^{H} / 4 .^{19}$

\footnotetext{
${ }^{18}$ A nalytically, this situation is akin the existence of an in..nite penalty for breach of contract, that is to say, a compensatory payment that is so high that, if it must be paid, it precludes any trade between the seller and the uncontracted customer. The role of I iquidated damages in our framework is analysed in Section 3.

${ }^{19}$ Alternatively but equivalently $L$ could be paid ${ }^{\mathrm{i}} v^{L}+v^{H}{ }^{\Phi} / 4$ to relinquish its exclusive right. This implies that in our full model embodying speci..c investment renegotiation of the exclusivity provision does not hamper the potential achievement of ...rst-best allocations. Hence presently renegotiation is both ex ante and ex post advantageous from an eф ciency point of view, as opposed to the cases pointed out by Tirole (1999) where it is, instead, ex post bene..cial but ex ante detrimental for investment incentives. The result that contracting might in some situations be eф ciency-improving even in the presence of ex post ren egotiation
} 
The following proposition states the resulting equilibrium payoxs to the parties.

P roposition 2 Suppose $S$ has an exclusive-dealing contract with $L$. Then in the limit, as $\$ ! 0$, the unique subgame-perfect equilibrium payoxs to $S, L$ and $H$ respectively converge to

$$
\frac{v^{H}+v^{L}}{4}, \quad \frac{v^{H}+v^{L}}{4} \text { and } \frac{v^{H} \mathrm{i} v^{L}}{2}
$$

So the equilibrium outcome is again Pareto ed cient and the good ultimately falls into buyer $H^{\prime}$ s hands. Also, observe that buyer $L$ now captures a strictly positive payo albeit he is the lowest-value buyer. The fact that this payo depends on $L$ 's own valuation will play a major role in our subsequent analysis, and indeed distinguishes our approach from previous models. M oreover, we ..nd that the nonexclusive buyer's bargaining payou is immune to the exclusionary provision. ${ }^{20}$ Exclusivity merely transfers rents from the seller (an indispensable player) to the exclusive-rightholder without having a negative externality on the excluded buyer [contrary to A ghion and Bolt on (1987), Segal and W hinst on (2000) and Segal (2003) ].21

$\mathrm{N}$ ext, consider the case in which the seller writes the exclusive contract with $H$. R esale is now irrelevant, and the surplus generated by trade simply consists of $v^{H}$. Hence, the entire game reduces to a two-party bargaining between the seller and buyer $H$. The following result is then immediate.

P roposition 3 Suppose $S$ has an exclusive-dealing contract with $H$. Then in the limit, as $\$ ! 0$, the unique subgame-perfect equilibrium payous to $S, L$ and $H$ respectively converge to

$$
\frac{v^{H}}{2}, \quad 0 \text { and } \frac{v^{H}}{2}
$$

Unsurprisingly, in the presence of exclusive dealing buyer $H$ pays a lower price for the item and his stake increases from ${ }^{1} v^{H} \mathrm{i} v^{L} / 2$ to $v^{H} / 2$. Note, however, that in this case $H$ 's extra payox does not depend upon $H$ 's use value but rather on $L^{\prime}$ 's.

Some of the conclusions in this section dixer markedly from those based on cooperative bargaining. First, we ..nd that if buyer $L$ holds an exclusive contract his expected payo increases with his use value, whereas in cooperative

\footnotetext{
seems to shed new light on traditional contract theory.

${ }^{20} \mathrm{~T}$ his means that the so-called negative bargaining exects on the uncontracted agent's payow identi..ed by Segal and W hinston (2000) and Segal (2003) do not obtain in our model.

${ }^{21}$ Although we do not explicitly deal with renegotiation issues, this is clearly a natural way in which ...nal payoxs might be obtained in a one-step fashion (see al so footnote 19). We include a brief discussion of this point in the subsequent section of the paper.
} 
bargaining it depends on the value created by coalition $\mathrm{f} S, H \mathrm{~g}$. Secondly, Segal and Whinston maintain that exclusivity gives rise to a negative externality on the uncontracted buyer because he now generates zero when paired with the seller (trade between the two parties is prohibited). Coalition formation and the ordering of players are the main forces driving their results. ${ }^{22}$ In our noncooperat ive bargaining model the negat ive externality on the uncontracted party does not obtain. Rather, an exclusive contract in principle harms the seller whose payou is lower than under a nonexclusive regime due to the suppression of initial competition between the buyers.

The next section uses these results to examine the link between exclusive trade agr eem ents and incentives to make relationship-speci... investments. For simplicity, we assume only one buyer has invest ment opport unities but our central message also applies if there are multiple investors (see the A ppendix for an example).

\section{Exclusivity and Investment Incentives}

We focus on a vertical structure comprising an input monopolist, denoted by $U$, and two downstream ..rms designated by $D_{0}$ and $D_{1} \cdot{ }^{23}$ The seller initially possesses a single indivisible unit of an essential input that the downstream units can tran sform into consum ption goods on a one-for-one basis. ${ }^{24}$ This means that $U$ is un productive with the input whereas $D_{j}, j=0,1$, is unproductive without the intermediate good. To simplify matters, we suppose throughout that the downstream units sell their respective products in independent markets.

Let $V_{j}$ stand for the aggregate surplus or "value" that $D_{j}$ generates in the consumption market when it has access to the intermediate good. Buyer $D_{0}$ has a known valuation of the input, $V_{0}$. This may rełect the application of a technology already patented by $D_{0}$ or prior investments in human capital, or just an intrinsic capability. For convenience we assume that $V_{0} 2(0,1)$. For buyer $D_{1}$, operating in a dixerent market, the value of the good depends on some yet to be undertaken speci..c investment, perhaps $R \& D$. The extent to which this succeeds in generating a viable process is uncertain. ${ }^{25}$ That is, $V_{1}$ is stochastic and also depends upon $D_{1}$ 's "noncontractible" exort level. We

\footnotetext{
${ }^{22}$ Cooperative bargaining solutions are also best justi..ed as incorp orating notions of justice or fairness, but this is not necessarily a basis for positive economics.

${ }^{23}$ Our model is somew hat a special case of Bolton and W hinston (1993). However, in that paper both dow nstream ...rms make relationship-sp eci..c investments and the authors are int erested in analysing optimal ownerwhip structures.

${ }^{24} \mathrm{~T}$ he case of a manufacturer signing an agreement to buy all its supplies from one of a number of upstream ..rms (Segal and W hinston's model) is analytically identical.

${ }^{25} \mathrm{~A}$ ghion and Tirole (1994) examine a related model in which a research unit performs noncontractible activities that increase the chances of discovery of an innovation. Their analysis concentrates though on bilateral relationships and optimal ow nership structures. Here, unlike A ghion and T irole's formulation, only one party makes a "sel..sh investment" and there are no cash constraints.
} 


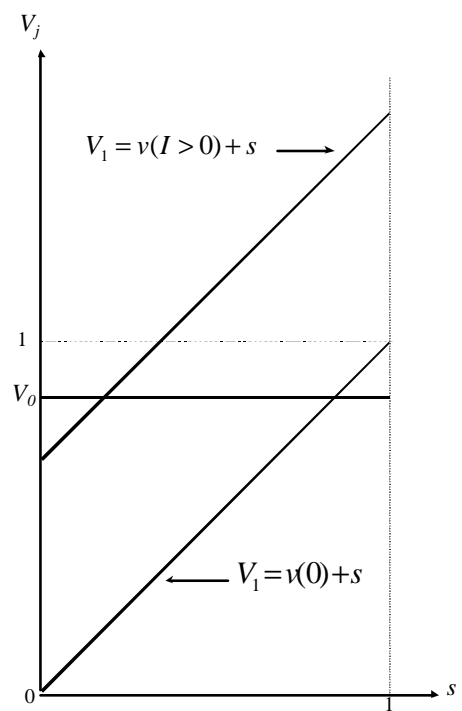

F igure 1: Relationship between the downstream ..rms' valuations

suppose that $D_{1}$ 's use value is additive

$$
V_{1}(I, s)=v(I)+s
$$

where $I 2 \mathrm{R}_{+}$is $D_{1}$ 's (unveri..able) investment level and $v$ is an increasing strictly concave function with the properties: $v(0)=0$ and $\lim _{I ! 1} v(I)<V_{0}$. The latter guarantees that there is always a positive probability of $D_{0}$ being the el cient buyer. We also assume that the expected marginal productivity of investment at its zero level is in...nite so as to guarantee interior solutions. The random variable $s$ is drawn from a density function $f(s)$ that is strictly positive on its support $[0,1]$.

The monetary equivalent cost of $D_{1}$ 's speci... investment is $c(I)$, where $c$ is an increasing st rict ly convex function with the foll owing properties: $c(0)=0$ and $c^{0}(0)=0$. Further, there are no production costs and resale of the intermediate input is feasible.

Figure 1 depicts the relationship between the downst ream ..rms' valuations. Note that the probability that $D_{1}$ is ex post the highest-value customer depends on both $D_{0}$ 's use value and $D_{1}$ 's exort level.

The sequence of events is illustrated in Figure 2. At date 1 ..rm $D_{1}$ invests, then the state of the world is realized, and subsequently there is a three-party bargaining session in which the allocation of the input and its transfer price are determined. Lastly, at date 4 , trade and production take place. The seller may 


$\begin{array}{ccccc}\begin{array}{c}\text { An exclusive } \\ \text { contract is } \\ \text { written }\end{array} & \begin{array}{c}\mathrm{D}_{1} \text { makes } \\ \text { specific } \\ \text { investment }\end{array} & \begin{array}{c}\text { Uncertainty } \\ \text { is resolved }\end{array} & \begin{array}{c}\text { Three-party } \\ \text { bargaining } \\ \text { takes place }\end{array} & \begin{array}{c}\text { Trade and } \\ \text { production } \\ \text { occur }\end{array} \\ \text { Date 0 } & \text { Date } 1 & \text { Date } 2 & \text { Date } 3 & \text { Date } 4\end{array}$

F igure 2: Sequence of events

write ex ante, at date 0 , an exclusive-dealing contract with $D_{1}$ that confers th is ..rm exclusive rights over trade with $U$. Following Segal and W hinst on (2000) and our discussion in Section 2, we assume that the exclusive contract exhibits some degree of incompleteness, in the sense that it does not specify in advance a positive trade between the parties to the contract. In fact this is a desirable feature of the contract allowing better incentives to emerge but there may be no choice over the issue. This may be because the exact nature of the input is ill-de..ned ex ante and so agents cannot cont ract for a speci..c delivery. T his is a standard assumption in the "incomplete contracting" literature [G rossman and Hart (1986), Hart and Moore (1990) and Hart (1995)]. ${ }^{26}$ The implication is that only the identities of trading partners are veri..able by courts; this assumption is not always applicable, but seems appropriate in many circumstances. ${ }^{27}$

We..rst study $D_{1}$ 's marginal investment incentives in the nonexclusive benchmark case. In the absence of exclusive dealing, $D_{1}$ captures ex post a positive bargaining payox only in those realizations in which it is the high-value buyer. Using Proposition $1, D_{1}$ 's payox is $\left(V_{1} \mathrm{i} V_{0}\right) / 2$ when $V_{1}, V_{0}$ and zero in the remaining states of the world.

Letting $S_{j}(I)^{\prime}$ f $I \mathrm{j} V_{j}, V_{i} \mathrm{~g}$ designate the set of states of the world in

\footnotetext{
${ }^{26}$ See Tirole (1999) for a comprehensive and critical discussion of the more recent developments in this literature.

${ }^{27} \mathrm{As}$ argued by $\mathrm{H}$ art and Tirole (1990), exclusive dealing can sometimes be unenforceable for either informational or legal reasons. In those situations vertical integration might be preferred to exclusivity. See the Conclusion for further discussion.
} 
which it is ed cient for $D_{j}$ to use the input, we write $D_{1}$ 's expected revenue as:

$$
\begin{aligned}
\pi_{1}(I, s) & =\mathrm{Z}^{\mu} \frac{V_{1} \mathrm{i} V_{0}}{2} f(s) d s \\
& =Z_{1}^{S_{1}} \cdot \frac{v(I)+s \mathbf{i} V_{0}}{2} f(s) d s
\end{aligned}
$$

where we used the fact that $V_{1}, V_{0}$ implies that $s, V_{0} \mathbf{i} v(I) . D_{1}$ 's optimal investment level is then characterized by the ..rst-order condition $\pi^{0} i c^{0}=0$, namely: ${ }^{28}$

$$
Z_{1} \cdot \frac{v^{9}\left(I^{n e}\right)}{2} \cdot f(s) d s=c^{0}\left(I^{n e}\right)
$$

where superscript "ne" stands for non-exclusive.

Next, note that a social planner chooses $I$ to maximize the expected aggregate surplus created by the vertical relationship, which in the case under consideration is given by:

$$
\begin{aligned}
W(I, s) & ={ }_{S_{0}} V_{0} f(s) d s+{ }_{S_{1}} V_{1} f(s) d s \mathbf{i} c(I) \\
& =\mathbf{Z}_{V_{0} \mathbf{i} v(I)}^{Z_{1}} V_{0} f(s) d s+{ }_{V_{0} \mathbf{i} v(I)}[v(I)+s] f(s) d s \mathbf{i} c(I)
\end{aligned}
$$

The ed cient (or "..rst-best") investment level is then characterized by the ..rst-order condition:

$$
\begin{aligned}
& Z_{1} \\
& V_{0 \text { i } v\left(I^{\natural}\right)} v^{0}\left(I^{\text {ळ})} f(s) d s=c^{0}\left(I^{\ltimes}\right)\right.
\end{aligned}
$$

Since $v^{0}(0)>c^{0}(0)$ and $0<V_{0}<1$, we conclude that $I^{\text {a }}>0$. Hence, by simply comparing equations ( 3 ) and (5) we have the following.

P roposition $4 \mathrm{In}$ the absence of exclusive dealing, $D_{1}$ is exposed to the threat of hold-up and underinvests relative to the ..rst-best level.

P roof. This follows directly from (3), (5), and the assumed properties of $v$ and $c$.

Underlying this result is the standard hold-up problem. Although $D_{1}$ pays the full marginal investment cost, it captures ex post only half of the marginal return on its investment. The rest is expropriated by $U$ in the trilateral bargaining process. Private investment returns are then smaller than the social ones and, under a nonexclusive regime, $D_{1}$ underinvests relative to the ed cient level.

O ur previous discussion established the benchmark "nonexclusive" and "socially optimal" outcomes. In the next subsection we analyse the impact of exclusivity on $D_{1}$ 's incentive for investment. Interestingly, exclusivity always promotes its recipient's incentives to make relationship-speci..c investments.

\footnotetext{
${ }^{28}$ We assume throughout that second-order conditions automatically hold.
} 


\subsection{Investment incentives in the presence of exclusivity}

Suppose the upstream monopolist writes an enforceable exclusive contract with $D_{1}$ that prevents $U$ from trading with any customer other than $D_{1}$. The price at which the good is exchanged is still bargained ex post and there is still the possibility of resale to $D_{0}$.

Propositions 2 and 3 imply that, in the presence of exclusivity, $D_{1}$ obtains a positive bargaining payox in all possible states of the world. More precisely, $D_{1}$ 's payoo is $V_{1} / 2$ when $V_{1}, V_{0}$ and $\left(V_{0}+V_{1}\right) / 4$ in the remaining states of the world.

$D_{1}{ }^{\prime}$ 's expected revenue is now:

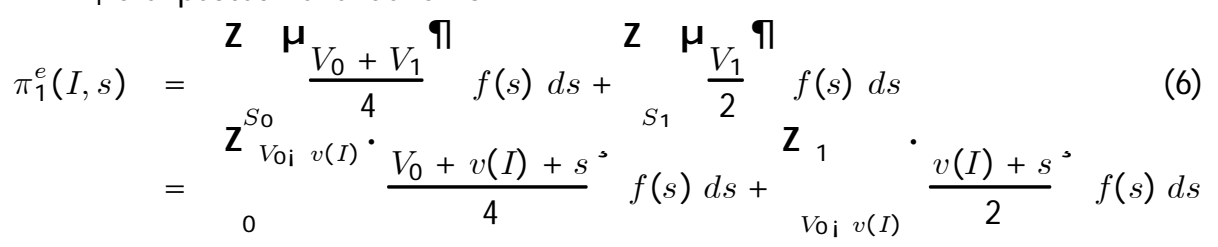

Under exclusivity, $D_{1}$ 's optimal investment choice is thus characterized by the ..rst-order condition:

$$
\mathrm{Z}_{V_{0 \mathrm{i}} v\left(I^{e}\right)}{\frac{v^{0}\left(I^{e}\right)}{4}}^{\nu} f(s) d s+{ }_{V_{0 \mathrm{i}} v\left(I^{e}\right)}^{\mathrm{Z}_{1}}{\frac{v^{9}\left(I^{e}\right)}{2}}^{\nu} f(s) d s=c^{0}\left(I^{e}\right)
$$

That is, $D_{1}$ captures not only half of the marginal returns on investment when $V_{1}, V_{0}$ (as in the nonexclusive benchmark), but also a quarter of the marginal investment return when the input ends up in $D_{0}{ }^{\prime} s$ hands. The latter increases in $V_{1}$ are not in principlesocially valuable, for the social bene..ts of $D_{1}$ 's investment only accrue when $V_{1}>V_{0}$. But the extra investment is potentially eф ciency-enhancing because count eracts the incentive for under investment (due to hold ups) existing when $D_{1}$ is ex post the highest-value buyer. So exclusivity unambiguously encourages $D_{1}$ 's speci..c investment.

The following proposition summarizes the main message of this paper. (It follows directly from the comparison of expressions (3), (5) and (7).)

P roposition 5 ( $T$ he Relevance Result) If the seller writes an exclusive-dealing contract with $D_{1}$, then the latter invests more than under a nonexclusive regime. So exclusivity unambiguously fosters $D_{1}$ 's relationship-speci... investment (i.e., $\left.I^{e}>I^{n e}\right)$.

It is worth comparing the rationale for Proposition 5 with that und erlying the "I rrelevance Result" obtained in earlier papers. In the cooperative frameworks utilized previously, exclusivity merely eliminates the surplus otherwise created by a coalition of the seller and the nonexclusive customer - in the presence of exclusive dealing they cannot trade. It is evident that the contracted buyer's bargaining payox must then go up. Whether this additional payox is sensitive 


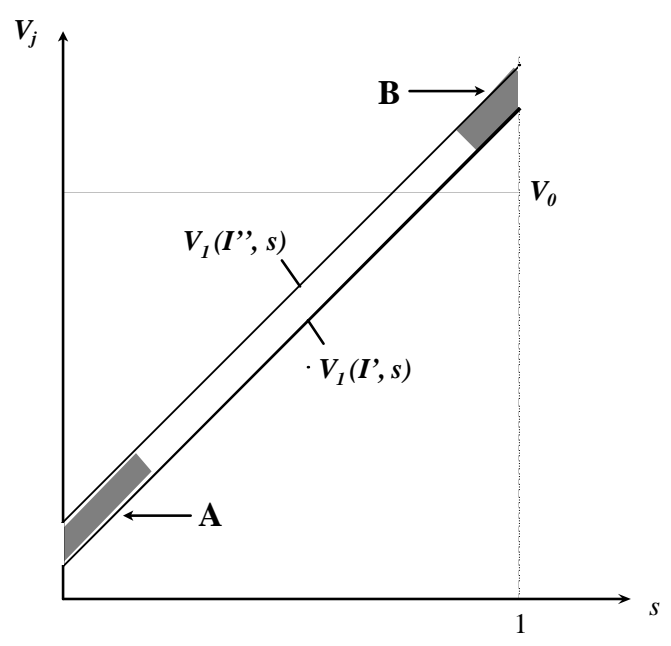

Figure 3: $D_{1}$ 's investment incentives in the presence of exclusive dealing

to the contracted buyer's investment level is less obvious. The point is that the value of coalitions which include the contracted ..rm is unchanged but the value of coalitions that do not include the contracted ..rm is reduced. Thus the surplus brought by the contracted ..rm relative to the nonexclusive case does not depend on the exclusive..rm's own use value. This is the basis for Segal and W hinston's result. On the other hand, the ..rst term of (7) implies that in our model $D_{1}$ 's extra payox does depend on its investment level even in the absence of cross-exects between ..rms. This stems from the contracted ..rm's (credible) threat of using the input internally when the lowest-value buyer. $D_{1}$ 's increased bargaining power is thus sensitive to its investment at the margin, and this is precisely the source of our "Relevance R esult".

Figure 3 illustrates the simple intuition behind this Relevance Result. Consider the change in $D_{1}$ 's expected payo when this ..rm holds an exclusivedealing contract and increases its investment from $I^{\prime}$ to $I^{\prime \prime}=I^{\prime}+\phi I$, for $\phi I$ in...nitesimally small. Roughly speaking, the area denoted by " $A$ " corresponds to the ..rst term of equation 7; it represents the expected change in $D_{1}$ 's return on investment when this ..rm is ex post the lowest-value buyer. In the absence of exclusivity this payox is zero. On the other hand, the area designated by " $\mathrm{B}$ " corresponds to the second term of equation 7. It illustrates the fact that $D_{1}$ captures only half of the marginal increases in $V_{1}$ when this ..rm is ex post the highest-value buyer. Note that if $A=B$ at the socially optimal investment level, then exclusive dealing yi elds the ..rst-best outcome.

In our set up it is clear that exclusivity can also give rise to overinvestment 
relative to the el cient level. This is because the contracted ..rm captures marginal investment returns even when the lowest-valuing buyer. If the exclusive ..rm is the less el cient buyer under most realizations a socially excessive level of investment obtains. It can be easily veri..ed that over investment relative to the...rst-best level arises in our model whenever $V_{0}$ i $v\left(I^{\natural}\right)>2 / 3$. The following proposition states this result.

P roposition 6 In the presence of exclusive dealing the contracted ..rm has incentives for overinvestment whenever $V_{0} \mathrm{i} v\left(I^{\not}\right)>2 / 3$, in which case $I^{e}>I^{\not \alpha}>$ $I^{\text {ne. }}$

W hen the condition identi..ed in Proposition 6 does not hold an exclusive contract certainly raises el ciency. W hen the condition is sat is.. ed a modi..cation of the exclusive contract sul ces to ensure that a ..rst-best outcome arises. This is shown in the next section.

Implicit in our approach is that the elcient contract will emerge as a result of prior negotiations between the three parties. What is required is that this pre-bargaining is itself elc cient. If so, the contract that will be agreed on will prevent one of the buyers from dealing directly with the seller. Though the exclusive contract has so far been treated as being signed between the seller and a buyer, a contract between the two buyers that only one of them is allowed to deal with the seller leads to identical incentive exects. A contract between the buyers may be per se illegal under competition laws, but if not it clearly undermines the bargaining power of the seller, implying the exclusive contract must be given away by the seller. ${ }^{29} \mathrm{~W}$ hen the buyers cannot easily collude, the seller will be able to extract a fee for the exclusive contract.

This concludes the main analysis of the current paper. In short, our overall message is that the relationship between an exclusivity provision and the incentive for speci... investment seems to be much more robust than existing models suggest.

\subsection{Liquidated damage provisions}

Thus far we have analysed exclusive contracts that completely block trade between the seller and the uncontracted buyer (i.e. involve in..nite penalties for external trade). In practice mor $\ddagger$ exible contracts are often written stipulating ..nite damages to be paid in the event of breach. In this section we relax our

\footnotetext{
${ }^{29}$ As p ointed out by J ones and Sufrin (2000), hor izontal agreements restricting the parties' freed om to negotiat e buying prices are bound to infringe A rticle 81 (1) of the E E C Treaty. For example, in the "Zinc P roducer Group" case (OJ L220/27, 1984) the E uropean Commission concluded that an agreement restricting the freedom of each member company to negotiate its purchase price of raw material was ill egal. More particularly, the co-ord inated individual buying up of zinc on the Lond on M etal $E$ xchange by the colluding companies was considered an infringement of Article 81 (1) owing to its alleged "restriction of competition".
} 
previous assumption and brieły examine contractual provisions that only specify liquidated damages, i.e., a ..nite compensation for breach of contract. Such liquidated damage clauses may have a positive role in our framework in curbing overinvestment. The reason is that such a provision bounds the number of states in which the contracted ..rm's payox, when the low-value buyer, depends on its marginal investment choice. When exclusive dealing gives rise to overinvestment, there exists an optimal breach penalty that induces the ..rst-best level of speci...c investment.

According to Spier and Whinst on (1995), two branches of literature exist with rather dixerent views of the role of liquidated damages: one argues that they are socially desirable because they protect relationship-speci..c investments, whilst the other asserts that they are socially undesirable because they exclude ed cient competitors. The analysis in the current paper leads to a striking third view, namely, that liquidated damage provisions are in general et ciency-enhancing because they "curb" the exclusive buyer's incentives for overinvestment.

Prior to considering investment decisions, the parties' ex post bargaining payous in the presence of damage payments will be examined. We focus again on the three-party bargaining game discussed in Section 2 . Let $d$ denote the (..nite) privately stipulated penalty for breach of the original contract.

First assume that the seller enters into an exclusive trade agrement with $L$. Using Proposition 2 we can immediat ely see that if $d \cdot{ }^{1}{ }_{v^{H}}+v^{L}{ }^{4} / 4$ the seller will $\mu$ nilaterally breach. Put dixerently, in the SPE of the game $S$ obtains ${ }^{1} v^{H}+v^{L} / 2 \mathrm{i} d$ independently of the buyer she trades with $\mathrm{T}$ hus, in the case under consideration, the good is sold to $H$ for $v^{H}+v^{L} / 2$, as under a nonexclusive regime, and the cont racted buyer gets paid the stipulated damage $d$. In this instance $L$ 's payou does not depend on its use value. If instead $d>{ }^{\mathrm{i}}{ }^{H}+v^{L} / 4$, then the model boils down to the (fully) exclusive regime analysed in Subsection 2.1, and therefore Proposition 2 applies. In summary;

P roposition 7 Suppose $S$ has an exclusive-dealing contract with $L$ that stipulates liquidated damages $d$. If $d \cdot{ }^{H}+v^{L} / 4$, then in the limit, as $\phi ! 0$, the unique subgame-perfect equilibrium payoxs to $S, L$ and $H$ respectively converge to

$$
\frac{v^{H}+v^{L}}{2} \mathrm{i} d, \quad d \text { and } \frac{v^{H} \mathrm{i} v^{L}}{2}
$$

If, on the other hand, $d>{ }^{\mathrm{i}} v^{H}+v^{L}{ }^{\Phi} / 4$, then Proposition 2 applies.

Proposition 7 casts doubts on the chief point made by Aghion and Bolton's (1987) infuential paper. In exect they interpret liquidated damage provisions as implicit fees that a future entrant (buyer $H$ in the above case) will have to pay the incumbents to access a particular market. In their model delivery is contractible ex ante and the damage payment generates social losses because the incumbents set a socially excessive level of damages to capture extra rents from 
the potential entrant, thereby blocking ec ciency-improving entry. In contrast, our analysis suggests that while stipulated damages for breach do redistribute bargaining power between the parties to the contract, they have no exect whatsoever on the nonexclusive party's payox. Since ed ciency-enhancing entry is not blocked, liquidated damage clauses turn out to be in principle neutral from a welfare point of view. Spier and Whinston (1995) have shown that the introduction of renegotiation alone destroys A ghion and Bolton's result, but they nevertheless conclude that damages for breach still create inec cient barriers to entry in the presence of relationship-speci..c invest ment due to the contracted agent's incentive for overinvestment. However, in our model with speci..c investment these provisions do have in general a positive role, insofar as they may induce the ..rst-best investment level (see below).

Let us look now at the case in which the seller writes an exclusive contract with $H$. From Proposition 3 it is immediate that if $d \cdot v^{L} / 2$, the seller will be willing to unilaterally breach the original contract and trade with either buyer. Since in equilibrium the item falls into $H^{\prime}$ 's hands, the contract is ultimately honoured and the liquidated damage is not paid along the equilibrium path. However, the provision still matters because it impinges on the agreed upon transfer price, which in the case under consideration is smaller than the one prevailing under a nonexclusive regime. W ith damages set at this level there is no SPE in which $H$ will pay the seller more than $v^{H}+v^{L}{ }^{4} / 2 \mathrm{i} d$ at the outset of the negotiations. If, however, $d>v^{L} / 2$, then the game boils down to a two-party bargaining between the parties to the contract, and therefore Proposition 3 applies.

P ropositi on 8 Suppose $S$ writes an exclusive-dealing contract with $H$ that stipulates liquidated damages $d$. If $d \cdot v^{L} / 2$ then in the limit, as $\phi ! 0$, the unique subgame-perfect equilibri um payox s to $S, L$ and $H$ respectively converge to

$$
\frac{v^{H}+v^{L}}{2} \mathrm{i} d, \quad 0 \quad \text { and } \quad \frac{v^{H} \mathrm{i} v^{L}}{2}+d
$$

If, on the other hand, $d>v^{L} / 2$, then Proposition 3 applies.

The remainder of this section examines the impact of stipulated damages for breach on the contracted ..rm's investment incentives. Speci..cally, suppose the seller writes an exclusive contract with $D_{1}$ that stipulates damages $d$. $\left(V_{0}+V_{1}\right) / 4$ for some subset of feasible values of $V_{1}$. Consider whether there exists a level of damage payment that not only protects speci...c investments but also curtails $D_{1}$ 's incentives for overinvestment arising under a "fully" exclusive regime. The answer turns out to be aф rmative (bear in mind that when $D_{1}$ holds an exclusive-dealing contract, it overinvests relative to the ec cient level if and only if $V_{0}$ i $\left.v\left(I^{\circledR}\right)>2 / 3\right)$.

To clinch the point, suppose $d<V_{0} / 2$ [which implies $4 d ; \quad V_{0} \mathrm{i} v\left(I^{\text {ฉ }}\right)<$ $\left.V_{0} \mathrm{i} v\left(I^{\natural}\right)\right]$. For notational convenience, let $s$ stand for $4 d ; V_{0} \mathbf{i} v(I)$. Then, 
using P ropositions 7 and 8 we can write $D_{1}$ 's expected revenue as:

$\pi_{1}^{d}={ }_{0}^{\mathrm{Z}_{s} \mu^{\mu}} \frac{V_{0}+V_{1}}{4} f(s) d s+{ }_{\sigma}^{\text {ๆ }} d f(s) d s+{ }_{V_{0} \mathrm{i} v(I)}^{\mathbf{Z}_{V_{0} \mathrm{i} v(I)}} \frac{\left(V_{1} \mathbf{i} V_{0}\right)}{2}+d f(s) d s$

The ..rst two terms of (8) refer to realizations in which $V_{0}$ exceeds $V_{1}$. E \& ciency then calls for the nonexclusive buyer to use the in put. The ..rst term of (8) covers cases in which $d,\left(V_{0}+V_{1}\right) / 4$ and therefore $D_{1}$ 's bargaining payox is $\left(V_{0}+V_{1}\right) / 4$ [using Proposition 7]. The second term of ( 8 ) refers to situations in which $d<\left(V_{0}+V_{1}\right) / 4$, which implies that $D_{1}$ 's bargaining payox is simply $d$ [again using Proposition 7]. F inally, the last term of (8) is due to the fact that when $d<V_{0} / 2$ and $V_{1}>V_{0}, D_{1}$ 's bargaining payox is $\left(V_{1} \mathbf{i} V_{0}\right) / 2+d$ [using Proposition 8].

$D_{1}$ 's optimal investment choice is therefore characterized by the ..rst-order condition:

$$
\mathrm{Z}_{4 d \mathrm{i} V_{0} \mathrm{i} v\left(I^{d}\right)} \frac{v^{9}\left(I^{d}\right)}{4} f(s) d s+{ }_{V_{0} \mathrm{i} v\left(I^{d}\right)}^{\mathrm{Z}_{1}} \frac{v^{9}\left(I^{d}\right)}{2} f(s) d s=c^{0}\left(I^{d}\right)
$$

Comparing equations (7) and (9), it is readily seen that ..nite - as opposed to in..nite - stipulated damages for breach are sometimes surplus-improving because they curb the contracted ..rm's incentives for overinvestment. The route is the introduction of an upper bound on the number of realizations in which $D_{1}$ gets positive marginal investment returns when the low-value user, because now there are states of nature in which $D_{1}$ receives just $d$.

As pointed out above, Spier and Whinston (1995) argue that renegotiable damage penalties may give rise to overinvestment by the contracted party. In a way our previous results con...rm their ..nding. However, the models dixer in many important respects. Following Aghion and B olton (1987), they assume that a buyer can write a "contract for delivery" with a seller who makes an unveri..able speci..c investment. The ex ante contract stipulates a "transfer price" and a damage payment in case of breach (i.e., quantities are veri..able). A more ed cient seller may randomly show up ex post. Spier and Whinston then use a Nash bargaining formulation in which the original contract determines the threat point of the renegotiation process between the incumbents. Also, and more crucially, the potential entrant is able to make a take-it-or-leave-it oxer to the buyer (this in exect precludes three-party bargaining). The latter assumption implies that in all states of nature the incu mbents receive the surplus jointly created. This in turn induces too high a level of investment in order to capture extra rents from the entrant. In a model with explicit three-party bargaining and incomplete contracting (i.e., unveri..able quantities), we also ..nd that high damage payments can give rise to socially excessive investment [whereas, in a similar context, Segal and W hinston (2000) deny any relationship between stipulated damages and speci..c investments]. It is precisely in those cases, though, that there exists an optimal damage payment that induces the ..rst-best investment and thus maximizes expected aggregate surplus. 
To illustrate we now present a numerical example. Suppose $V_{1}=I+s$, $c(I)=(3 / 4) I^{2}$ and $V_{0}=11 / 12$. The random variable $s$ is uniformly distributed within the interval $[0,1]$. It can then be shown that the ..rst-best outcome is $I^{\mathfrak{k}}=1 / 6$. Further, since $I^{n e}=1 / 24$ and $I^{e}=13 / 60$, we have $I^{e}>I^{\mathfrak{\alpha}}>I^{n e}$. Under a fully exclusive regime $(d=1), D_{1}$ overinvests relative to the ec cient level (note that $V_{0}$ i $I^{\not \alpha}=3 / 4>2 / 3$ ). However were stipulated damages for breach ..xed at $d^{\infty}=19 / 48, D_{1}$ would invest at exactly the socially optimal level. As explained above, the optimal breach penalty establishes an upper bound $s^{\mathfrak{a}}=4 d^{\mathfrak{\alpha}} \mathrm{i} V_{0} \mathrm{i} I^{d}=1 / 2$ on the set of states of nature in which $D_{1}$ gets positive investment returns when $V_{1}<V_{0}$, so as to just compensate the contracted ..rm for the expected hold ups arising when it does end up using the good.

\section{Conclusion}

This paper shows that the relation ship-speci..c investment of a downst ream ..rm may be encouraged by a contract that prevents the upstream supplier of an essential input from selling it to another buyer. Of course this does not mean that the input will end up being used by the ..rm with the exclusive right to buy, but the contract does enhance the downstream ..rm's ex post bargaining power enabling it to extract an increased share of the value created by its investment. In particular, when the contracted ..rm is not the highest-value user of the input, the price at which it can resell it (or which it must be paid to relinquish the exclusive contract) is increasing in its own use value. This oxsets the underinvestment incentive due to the usual hold-up problem that arises when the contracted buyer is the highest-value user. Since the ..rm's investment is only socially productive when it does get to use the input, an exclusive-dealing contract may therefore result in excessive investment. This can be avoided by a provision that the seller can void the contract on payment of a ..xed fee set ex ante. W hen the contracted ..rm's use value is low, this provision is utilized by the seller, so in these states the ..rm's payox is no longer dependent on its investment.

An exclusive contract is not the only way investment incentives can be altered. Sometimes the downstream .rm may be able to buy in put prior to the investment decision (in exect backward integration). The owning ..rm now captures the full marginal bene..t of investment when it is the high value user, but also gains something from investment when it is the low-value user. The good is still sold on in these circumstances, but by increasing the owner's use value investment improves its terms of trade. There is thus overinvestment and to a greater extent than an exclusive contract would generate [see, e.g., Bolton and W hinston (1993)]. So an exclusive contract could "beat" backward integration and non-integration with no ex ante contractual relationship.

The semi-cooperative bargaining adopted in other papers fails to ..nd a role for exclusive contracts because a ...rm's payou only depends on the value its presence adds to a coalition. Holding an exclusive contract increases the number 
of coalitions to which a ..rm adds value, but if exclusivity makes a dixerence to whether a ..rm contributes to surplus, the contracted ..rm is the low-value user so its investment does not in $¥$ uence coalition value and yields no private return. When a ..rm is the high-value user, if it has an exclusive contract removing it from the grand coalition means the seller and the other buyer cannot produce at all, but leaves unchanged the marginal contribution of investment. So under cooperative bargaining, exclusivity does not boost the marginal return to investment.

N on-cooperative bargaining is not only more reasonable given non-cooperative investment, it establishes a new role for exclusive contracts in protecting the returns to marginal investment. ${ }^{30}$

The assumptions of the paper can be relaxed in various ways. In A ppendix A. 1 a dixerent bargaining protocol is applied leading to the Outside 0 ption Principle holding. We show that our main conclusion still applies. Sometimes ..rms have discretion which potential partner bene..ts from its investment. A ppendix A. 2 shows that exclusive contracts can el iminate the strategic ined ciencies that otherwise occur. A new potential eф ciency gain from exclusivity clauses arises when more than one potential partner is able to undertake relationship-speci... investment. A ppendix A.3 presents an example in which both buyers may invest. When there are multiple Nash equilibria in the investment game exclusive dealing may eliminate inec cient equilibria in which too many ..rms invest too little. ${ }^{31}$

In many cases exclusive contracts between ..rms involve investments that are partly generally. In our benchmark case of two buyers it is easy to see that if the investment of one buyer boosts the value of the good to the other buyer this diminishes the incentive to invest when there is no exclusive contract (it increases the price paid for the input) but, with the possibility of resale, spill overs increase investment incentives under exclusivity. So alt hough to make the novel analytical point we assume relationship-speci..c investment, the exects we consider can coexist with and augment the usual horizontal externalities argument.

Exclusivity may also confer other bene.ts. By providing a return even when investment fails, exclusive dealing provides insurance, which may be important for risk-averse ..rms.

Perhaps the most important application of the ideas in the paper is to employment contracts. What de.nes an employee is that they cannot sell their output to other ..rms. Moreover, even if in the absence of statutory employment provision ..rms typically constrain themselves from replace workers at will. R elative to self employment, the exect may be to stimulate relationship-speci..c employment.

Holmström and Roberts (1998) argue that "contractual assets" can often

\footnotetext{
30 Whenever exclusi ve dealing promotes ec ciency it will tend to be adopted since the gains will be shared between the parties in the ex ante bargaining over contractual terms (a refection of the Coase Theorem).

${ }^{31}$ A similar point is made by de Meza and Selvaggi (2003), albeit our working paper follows the existing literature in assuming cooperative bargaining.
} 
provide the same redistribution of bargaining power that the property rights theory of the ..rm normally attributes to physical assets. The current paper formalizes this notion by setting forth a model where exclusive dealing emerges as a powerful governance structure for enhancing its recipient's incentives to make relationship-speci..c investments. 


\section{Appendix}

\section{A.1. O utside-option bargaining}

Consider a two buyer one seller set up as discussed in the main text except that instead of an exogenous risk of breakdown in negotiations there is discounting between rounds. As before, resale is feasible. Since the good is non-durable and only of value when consumed, the outside-option principle applies. For the sake of conciseness, we focus throughout on the parties' subgame-perfect equilibrium payoxs for the case in which the interval between successive oxers becomes vanishingly small. (A thorough discussion of this bargaining model can be found in Selvaggi 2003, Section 3.)

Suppose $H$ and $L$ value the good at 12 and 10 respectively. Then, in the absence of exclusive dealing the item is instantly sold to $H$ for 10 [note that similar conclusions are obtained by 0 sborne and Rubinstein (1990), Bolton and Whinston (1993) and B inmore (2003)]. The rationale for this equilibrium out come is exactly the same as in the breakd own case; namely, resale means that $L$ will be willing to pay up to the SPE price of the resale game at the outset of the negotiations with the seller. That resale value is equal to 10 because if the game reaches the secondary market $L$ possesses the "binding" outside option of consuming the good (i.e., $10>0.5 \pm 12$ ). Consequently, the ..nal bargaining payous to $S, L$ and $H$, respectively, are 10,0 and 2 .

Now assume that before bargaining takes place, the seller enters into an enforceable exclusive trade agreement with buyer $L$. As a result of this contract, the ..rst-stage game reduces to a two-party bargaining process between the seller and the contracted buyer in which they split the relevant gains from trade equally (notice that both parties' outside options are zero). In the case under consideration that surplus equals 10 . Hence, the item is initially sold to buyer $L$ for $0.5 £ 10=5$ and this buyer then resells the object to buyer $H$ for 10 . In the frictionless limit, the parties' equilibrium payoxs are therefore 5 to the seller, 5 to buyer $L$ and 2 to buyer $H$. Two main features of this result are worth stressing. First, note that as before, exclusivity does not have any negative externality on the nonexclusive buyer. Secondly, in the presence of exclusive dealing, buyer $L$ 's bargaining payou is again sensitive to his own use value whenever $L$ 's outside option at the second-stage subgame is binding. It is therefore immediate that an exclusivity deal axects its recipient's incentive for relationship-speci... investment at the margin.

Suppose a ..rm can undertake risky $R \& D$. A low-level investment program yields with equal chance a value of the input of 22 or 8 . Higher investment boosts value to 24 or 10 . An established ..rm values the in put at 12 . Without an exclusive contract the expected value of investment is 1 but with exclusivity expected value equals 2 , the expected increase in the social value of investment.

\section{A.2. Exclusivity and Strategic Investment}

As in the main text, suppose the seller of a unit of an indivisible item confronts two heterogenous buyers. There is, however, no uncertainty. Buyer 1 values the good at $\hat{v}$ whereas buyer 2 values the good at $v_{2}>\hat{v}$. When the 
outside-option principle applies the item is sold to buyer 2, the high-value type, at a price $\hat{v}$ (i.e. $\hat{v}, v_{2} / 2$ so the seller's outside option is binding). Suppose the seller can undertake some discrete relationship-speci..c investments. Let $\phi \hat{v}$ and $\phi v_{2}$ represent the respective boosts in the buyers' valuations when the seller invests at cost $i_{1}$ and $i_{2}$ respectively, and assume that $\phi \hat{v} \cdot \phi v_{2}$ and $\hat{v},\left(v_{2}+\phi v_{2}\right) / 2$.

It is ed cient to undertake the investment that raises buyer 2's use value as long as $i_{2}<\$ v_{2}$. Also, note that undertaking investment $i_{1}$ is always socially unproductive. Since in the absence of an exclusive-dealing contract with buyer 2 , the seller obtains positive returns only on the investment that increases $\hat{v}$ ( unless $i_{2}$ raises the value of the good to buyer 2 in excess of $2 \hat{v}$, in which case the seller gets $0.5 f v_{2}$ ), $i_{2}$ will not be undertaken even though it is el ciencyimproving. If $i_{1}<\downarrow \hat{v}$, then the seller chooses the wrong investment because it in $\neq$ uences his bargaining power and thereby the price obtained for the good.

An exclusive-dealing contract signed between the seller and buyer 2 results in the seller obtaining $50 \%$ of the returns to the relationship-speci..c investment that increases buyer 2's use value. The seller's outside option is now zero and so the incentive to make the wrong investment $i_{1}$ - that is, the one that boosts the value of the good to buyer 1 - is eliminated. Since both changes are el ciencyenhancing, an exclusive contract will be adopted if the seller is the only party with investment opportunities. There is though a potential drawback. In the absence of an exclusivity provision the price of the object is ..xed at $\hat{v}$ independently of buyer 2's investment, who therefore captures the full extra value of any relationship-speci..c investment he may undertake. Ther efore the exect of exclusivity is to demotivate the buyer but to motivate the seller (and, in addition, to eliminate the seller's incentive to make wasteful investments to increase the value of the good to the alternative user). E qualizing both parties' investment incentives may well raise el ciency, in which case an exclusivity provision increases aggregate surplus.

Under "split-the-dixerence bargaining" the el ciency gains derived from exclusive dealing are lower. In exect each party get s $50 \%$ of the extra value its own investment creates whether or not an exclusionary contract is signed. Hence, there is no direct incentive for exclusive dealing. An exclusive contract does eliminate socially unproductive expenditures, however. Since the seller bene..ts from increases in the low-type agent's valuation because this forces up the price paid by the successful buyer, exclusivity eliminates the seller's incentive to expend resources to make the good more attractive to the lowest-val uing buyer in order to improve her bargaining position. Y et, once the exects of investment are stochastic even with split the dixerence bargaining an exclusive-deal ing contract may have direct bene..ts in encouraging relationship-speci..c investment.

This analysis is in general ap plicable not only to trade between ..r ms but also to employm ent contracts ( what follows is partially based on B aker et al. (2002) which in turn is in the spirit of GHM ). Interpret the supplier as a worker utilising an asset to produce a good of potential value to two ..rms. W ithout access to the asset the worker's investment is useless. One possibility (integration) is that the worker is an employee of buyer 2 who owns the asset. A nother possibility is 
outsourcing, that is the worker owns the asset and so is an independent supplier. The former arrangement eliminates the worker's incentive to undert ake wast eful investments to increase bargaining power but also implies there is no reason to make the productive investment. Our analysis adds to the Baker et al. menu; the best organisational form may be outsourcing (the worker owns the asset) but the buyer has an exclusive contract with the supplier. In exect exclusivity not only eliminates the seller's incentives to make $i_{1} \mathbf{i}$ type investment that is socially unproductive, but may encourage ec cient $i_{2} \mathrm{i}$ type investment. The latter exect is absent from a spot employment contract. Thus, without imposing any additional informational assumptions to the model we ..nd that exclusivity is in fact better than spot employment (i.e, integration).

\section{A.3. Exclusivity as a selection device}

Suppose that both buyers are ex ante symmetric and may choose to invest either "low", or "high" or not at all. A non-investing buyer is unproductive. There are two equally likely states of nature. If a buyer invests low, then the good is worth 12 in one state and nothing in the other. For simplicity, suppose that when both buyers invest low their payous occur in dixerent states (perhaps they operate indoor and outdoor restaurants, and the uncertainty is due to the weather). This assumption is not necessary for our results, however. If on the other hand a buyer invests high, then he values the object at 12 no matter which state prevails. Costs are 2.5 and 3.5 for "low" and "high" investment respectively. To ..x ideas, we focus throughout on pure-strategy Nash equilibria.

W ithout exclusive dealing there is an equilibrium in which both buyers invest low. In exect our bargaining solution implies that a customer pays 6 for the good in the state in which his investment succeeds. Thus, investing low yields expected net payou of 3 i $2.5=0.5$. Consider next a buyer's deviation to high investment when the other buyer invests low. The deviant pays 6 when his rival's investment fails. In the realization in which both investments succeed there is stixer competition for the provision of the good. Both buyers value the item at 12, and our bargaining solution involves the item being sold to either buyer for 12 and the seller capturing the entire surplus. This means that a deviation to "high" is not pro..table.

There are, however, other two (corner-type) Nash equilibria in which one buyer invests "high" and the ot her remains inactive. These allocations maximize aggregate surplus. To show that they constitute $\mathrm{N}$ ash equilibria, note that the investing party expects to pay 6 for the good in both states of the world. Thus, his expected net payo is 6 i $3.5=2.5$. A deviation to "low" implies that the investing party is now productive in only one state, which gives an expected net payo of 3 i $2.5=0.5$. So he does not gain by deviating. Using similar arguments, it can be shown that the non-investing party has no incentives to deviate either (expected payous are negative for either investment level).

An exclusive trade agreement removes the inec cient two-active ..rms equilibrium, i.e., only the surplus-maximising allocation in which a single buyer invests high survives exclusivity. Interestingly, exclusivity does not necessarily implies that the contracted buyer is the only potential investor. Indeed, there is 
an exclusive equilibrium in which the uncont racted buyer invests high and the exclusive buyer does not invest at all. Let us brieły look at this case. We know from the above arguments that the uncontracted customer has no incentives to deviate from "high" when his rival is not active - for exclusivity does not axect the uncontracted party's bargaining payox. So, we shall demonstrate that the exclusive buyer has no incentives to deviate either. If he does not invest, expected revenue is 3 . This stems from the fact that the resale price is 6 in both states of the world and he splits the dixerence between 6 and 0 with the seller. D eviations to "low" and "high" investments give him respectively expected net payoxs of $4.5 ; 2.5=2$ and 6 ; $3.5=2.5$. Since both are smaller than 3 , they are not pro..table. There is of course another $N$ ash equilibrium in which only the protected buyer invests "high". But the bottom line of our analysis is that both 'exclusive' equilibria achieve the et cient outcome.

The equilibrium in which the contracted buyer is in the end not active may nonetheless be eliminated through the initial negotiations over which one of them obtains the access privilege. M ore speci..cally, observe that if the buyers cannot contract with each other, then the seller can capture all the expected surplus by auctioning ex ante the exclusive-dealing contract. In exect the input is sold for 3.5 up-front with a further 6 paid on delivery. Hence, the exclusive contract also allows for full rent capture ${ }^{32}$.

\footnotetext{
${ }^{32} \mathrm{~T}$ he aforementioned shows that exclusivity can most often be used as a purely rentextraction device, as previously noted by Aghion and Bolton (1987), Bernheim and Whinst on (1998) and de M eza and Selvaggi (2003).
} 


\section{R eferences}

[1] A ghion, P. and B olton, P. (1987): "Contracts as a Barrier to Entry", American Economic Review, Vol. 77, pp. 388-401.

[2] A ghion, P. and T irole, J . (1994): "T he M anagement of Innovation", Quarterly J ournal of E conomics, Vol. 109, pp. 1185-1209.

[3] Baker, G., Gibbons, R. and Murphy, K. (2002): "Relational Contracts and the Theory of the Firm", Q uaterly J ournal of Economics, Vol. 117, pp. 39-84.

[4] Bernheim, B. and W hinston, M.D. (1998): "Exclusive D ealing", J ournal of Political Economy, Vol. 106, pp. 64-103.

[5] Besanko, D. and Perry, M. K., (1993): "Equilibrium Incentives for Exclusive Dealing in a Dixerentiated Products Oligopoly", RAND J ournal of Economics, Vol. 24, pp. 646-667.

[6] Binmore, K. (1985): "Bargaining and Coalitions", in A. Roth (ed), GameTheoretic M odels of Bargaining, Cambridge University Press, pp. 269-304.

[7] Binmore, K. (1994): "Bargaining Theory without Tears", Investigaciones E conómicas, Vol. 18, pp. 403-419.

[8] Binmore, K. (2003): Fun and Games, 2nd Edition, Houghton M i- in. (Unpublished draft.)

[9] Binmore, K., Rubinstein, R. and Wolinsky, A . (1986): "T he Nash Bargaining Solution in Economic Modelling", RAND J ournal of Economics, Vol. 17, pp. 176-188.

[10] Bolt on, P. and W hinston, M. D. ( 1993): "Incomplete Contracts, Vertical Integration, and Supply A ssurance", Review of E conomic Studies, Vol. 60, pp. 121-148.

[11] Calvó-A rmengo, A . (1999): "A N ote on Three-P layer N oncooperative Bargaining with Restricted Pair wise M eeting", E conomics Letters, Vol. 65, pp. 47-54.

[12] Che, Y . and Sákovics, J . (2003a): "A Dynamic Theory of Holdup", Econometrica (forthcoming).

[13] Che, Y . and Sákovics, J . (2003b): "Investment Dynamics and Contractual Remedies to the Holdup Problem", M imeo, E din burgh School of E conomics.

[14] Chiu, Y. S. (1998): "Noncooperative B argaining, Hostages and Optimal A sset Ownership", A merican E conomic Review, Vol. 88, pp. 882-901.

[15] de Meza, D. and Lockwood, B. (1998): “Does A sset O wnership A lways M otivate M anagers? Outside Options and The Property R ights Theory of the Firm", Quarterly J ournal of Economics, Vol. 113, pp. 361-386. 
[16] de Meza, D. and Selvaggi, M. (2003): "P lease Hold M e Up: Why Firms Grant Exclusive-D ealing Contracts", CM PO W orking Paper 03/066, University of B ristol.

[17] Frasco, G . (1991): Exclusive Dealing: A Comprehensive Case Study, London: University Press of A merica.

[18] Grossman, S. and Hart, O. (1986): "The Costs and Bene.ts of Ownership: A Theory of Lateral and Vertical Integration", J ournal of Political Economy, Vol. 94, pp. 691-719.

[19] Grout, P. (1984): "Investment and Wages in the A bsence of Binding Contracts: A Nash Bargaining A pproach", Econometrica, Vol. 52, pp. 449-460.

[20] Hart, O. (1995): Firms, Contracts and Financial Structure, Oxford: Oxford University Press.

[21] Hart, O. and Moore, J. (1990): "Property Rights and the Nature of the Firm," J ournal of Political Economy, Vol. 98, pp.1119-1158.

[22] Hart, O and Tirole, J. (1990): "Vertical Integration and Market Foreclosure", Brookings Papers on Economic Activity: Microeconomics, pp. 205286.

[23] Hendon, E. and Tranæs, T. (1991): "Sequential Bargaining in a Market with One Seller and T wo Dixerent Buyers", G ames and Economic B ehavior, Vol. 3, pp. 453-466.

[24] Holmström, B. and Roberts, J . (1998): "The Boundaries of the Firm Revisited", J ournal of E conomic Perspectives, Vol. 12, pp. 73-94.

[25] Jones, A and Sufrin, B. (2000): EC Competition Law: Text, Cases, and $M$ aterials, O xford: Oxford Universit Press.

[26] Klein, B. (1988): "Vertical Integration as Organizational Ownership: The Fisher B ody-G eneral M otors R elationship R evisited" , J ournal of Law, E conomics and Organization, Vol. 4, pp. 199-213.

[27] Klein, B., Crawford, R. and Alchian, A. (1978): "Vertical Integration, A ppropriable Rents, and the Competitive Cont racting Process", Journal of Law and Economics, Vol. 21, pp. 297-326.

[28] K lein, B . and Saft, L. (1985): "T he Law and E conomics of F ranchise Tying Contracts", J ournal of Law and E conomics, Vol. 28, pp. 345-361.

[29] Marvel, H. P. (1982): "Exclusive Dealing", J ournal of Law and E conomics, Vol. 25, pp. 1-25.

[30] Masten, S. E. and Snyder, E. A . (1993): "U nited States ver sus U nited Shoe Machinery Corporation: $\mathrm{O}$ n the Merits", J ournal of Law and Economics, Vol. 36, pp. 33-70. 
[31] M athewson, F. and Winter, R. (1987): "T he Competitive E xects of Vertical A greements: Comment", American Economic Review, Vol. 77, pp. 10571062.

[32] Mathewson, F. and Winter, R. (1994): "Territorial Restrictions in Franchise Contracts", E conomic Enquiry, Vol. 32, pp. 181-192.

[33] M cA fee, R.P. and Schwartz, M. (1994): "O pportunism in M ultilateral Vertical Contracting: Nondiscrimination, Exclusivity, and Uniformity", American Economic Review, Vol. 84, pp. 210-230.

[34] Motta, M. (2004): Competition Policy: Theory and Practice, Cambridge University Press, U.K.

[35] Muthoo, A . (1999): B argaining Theory with A pplications, Cambridge University Press, U.K.

[36] Osborne, M.J . and Rubinstein, A . (1990): B argaining and Markets, A cademic Press, USA.

[37] Rubinstein, A. (1982): "Perfect Equilibrium in a Bargaining Model", Econometrica, Vol. 50, pp. 97-109.

[38] Rubinstein, A . and Wolinsky, A. (1987): "Middlemen", Quarterly J ournal of Economics, Vol. 102, pp. 581-594.

[39] Segal, I. (2003): "Collusion, Exclusion, and Inclusion in Random-Order Bargaining", Review of E conomic Studies, Vol. 70, pp. 439-460.

[40] Segal, I. and W hinst on, M. D. (2000): "Exclusive C ontracts and Protection of Investments", RAND J ournal of E conomics, Vol. 31, pp. 603-633.

[41] Selvaggi, M. (2004): "Sequential B argaining with Resale in a Market with One Seller and T wo Buyers: Theory and Applications", mimeo, CMPO University of Bristol.

[42] Spier, K. and Whinston, M.D. (1995): "On the $E \varnothing$ ciency of Privately Stipulated Damages for B reach of Contract: Entry Barriers, R eliance, and Renegotiation", RAND J ournal of Economics, Vol. 26, pp. 180-202.

[43] Stole, L. and Zwiebel, J. (1996): "Intra-Firm Bargaining under NonBinding Contracts", Review of E conomic Studies, Vol. 63, pp. 375-410.

[44] Tirole, J . (1999): "Incomplete Contracts: Where DoWe Stand?", Econometrica, Vol. 67, pp. 741-781. 